\title{
News sentiment and the investor fear gauge
}

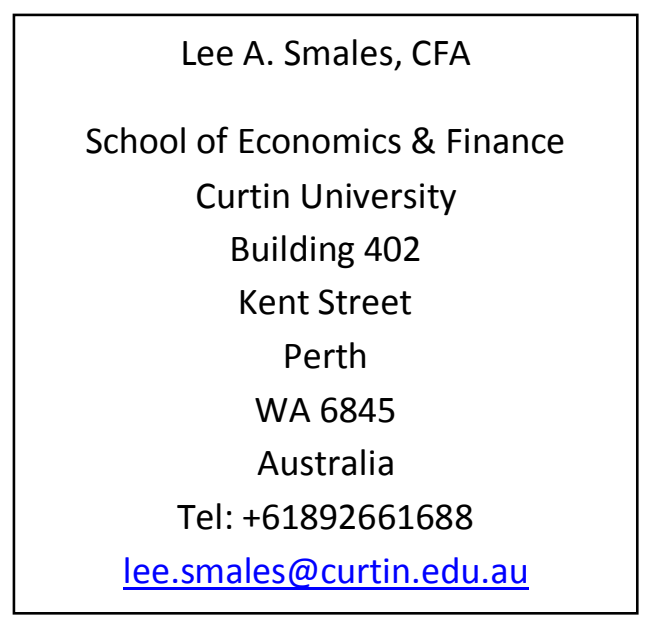

This note examines the relationship between aggregate news sentiment and changes in the implied volatility index (VIX). A significant negative contemporaneous relationship between changes in VIX and news sentiment is discovered. The relationship is asymmetric whereby changes in VIX are larger following the release of negative news items. 


\section{Introduction}

Often referred to as the "investor fear gauge", the market volatility index [VIX] expresses a consensus view about expected future stock market volatility; the higher the VIX, the greater the fear in the market. Prior work has considered the relationship between the implied volatility index and stock market returns. Fleming et al. (1995), Whaley [2000] and Giot [2005] find a significant negative and asymmetric contemporaneous relationship between stock returns and changes in implied volatility; VIX increases more as the S\&P500 index falls than it decreases when the S\&P500 index rises. The leverage hypothesis of Black [1976] has been favoured as the explanation for this risk-return relationship.

A related field of work in financial economics has considered the impact of news arrival on stock returns and volatility of those returns, identifying that the arrival of firm-specific news can drive movements in both stock prices and volatility. Earlier research focused on scheduled news, such as dividend announcements and earnings results. For example, Patell and Wolfson [1984], and Woodruff and Senchak [1988] find that much of the market adjustment occurs in the first 30 minutes following corporate announcements. More recently, the contextualisation and quantification of news content has enabled the identification of a wider range of news events. The relevance and sentiment of news has been tested in a variety of market settings with reference to stock returns. Tetlock et al. [2008] find that a quantitative measure of language can predict firms' earnings and stock returns, Dzielinski [2011] finds that positive (negative) news results in above (below) average returns. Groß-Klußmann and Hautsch [2011] and Smales [2012] find that highrelevance news induces an increase in market activity, with negative news sentiment having a greater impact than positive news. Prior work has yet to investigate whether aggregated firmspecific news has an empirical relationship with the implied volatility of an overall market index.

This note intersects these two developing avenues of economic research and investigates the empirical link between the release of firm-specific news and implied volatility indices. More precisely, I seek to examine the contemporaneous relationship between unscheduled aggregate news releases and changes in implied volatility. Aggregating news sentiment for the constituents of the S\&P 500 Index, over the period 2000 - 2010, I examine the relationship between news sentiment and changes in the index of implied volatility (VIX). I find a significant negative relationship between news sentiment and changes in VIX, with positive (negative) news related to a decrease (increase) in VIX; the relationship is much stronger during the financial crisis period of 2007-2009. I find evidence of an asymmetric effect whereby the magnitude of the change in VIX is larger during periods of negative news. 


\section{Data}

\section{$2.1 \quad$ News Sentiment}

Several vendors offer software tools that electronically analyse textual information in news releases using linguistic pattern recognition algorithms; words are translated into indicators of the relevance, novelty and sentiment of the news item. Pre-processed news data is gathered from a news analytics tool called Ravenpack, which utilises news items posted on the Dow Jones newswire and in the Wall Street Journal. News arrival is recorded with GMT time stamps with up to a millisecond precision. Prior work demonstrates that news that is highly relevant, and novel, induces a greater impact on asset prices. I therefore include only news items that are published for the first time and classified as highly relevant. This produces $2,138,342$ news headlines for S\&P 500 Index stocks over the period 04 Jan 2000 to 31 Dec 2010; unsurprisingly, noticeable spikes in the number of news items have occurred around events such as the terrorist attacks on 11 Sep 2001, and the demise of Lehman Brothers in 2008.

Ravenpack's Multi-Classifier for Equities (MCQ) sentiment indicator provides the focus for this study ${ }^{1}$. A score of 0 is assigned to firm-specific news with negative sentiment, 50 to neutral and 100 to positive; my analysis scales the scores to the more intuitive levels of $-1,0,+1$. The firmspecific MCQ score is utilized to create an aggregate measure of news sentiment by averaging the firm-specific MCQ for the given interval, $t$, for all 500 companies that make up the S\&P 500 Index in each period. I use the average MCQ score rather than simply aggregating the scores to account for intervals which naturally have a higher (or lower) degree of news releases, such as the quarterly earnings season or periods around public holidays ${ }^{2}$. Table 1 shows that the average daily news sentiment score is -1.1 , although this varies significantly during the sample period with a low of -59.7 in 2007, and a high of +38.0 in 2003.

$<$ Insert Table 1 $>$

\subsection{Implied Volatility Index (VIX)}

$V I X^{3}$ is an index computed on a real time-basis throughout each trading day, estimating the level of implied volatility by averaging the weighted prices of SPX puts and calls over a wide range of strike prices ${ }^{4}$, and thus representing expected market volatility over the next 30 calendar days. The VIX is quoted in percentage points and translate, roughly, to the expected movement in the S\&P 500

\footnotetext{
${ }^{1}$ Additional information on Ravenpack's classifiers can be found at http://www.ravenpack.com/

${ }^{2}$ The analysis is repeated using aggregate MCQ for each interval and qualitatively similar results are achieved.

${ }^{3} \mathrm{CBOE}$ and TRTH ticker symbol VIX.

${ }^{4}$ For a full explanation of the methodology see http://www.cboe.com/micro/vix/vixwhite.pdf
} 
Index over the next 30-day period, which is then annualized. For example, if the VIX is 20 , this represents an expected annualized change of $20 \%$ over the next 30 days; thus one can infer that the index options markets expect the S\&P 500 to move up or down 5.77\% (20\% / V12) over the next 30day period. Portfolio insurers, who routinely buy index puts are the largest constituent of the S\&P 500 Index option market; hence it is likely that it is put buyers who help to drive changes in implied volatility (VIX) and provides the index with the colloquial term - the "fear gauge".

To coincide with the availability of news sentiment data, VIX data is collected from Thomson Reuters Tick History for the period January 2000 - December 2010. Table 1 provides summary statistics for VIX; the mean level over the whole sample period is 23.19 although this ranges from a 2005 mean of 12.80 to a 2008 mean of 32.74 (and a closing high of 80.86 on 20 Nov 2008).

\section{The contemporaneous relationship between news and implied volatility}

I investigate the contemporaneous relationship between aggregated news releases and changes in the implied volatility index at daily and intra-day intervals. It is important to note that in utilising contemporaneous specifications I do not wish to imply causality, but instead seek to examine the reliability of statistical relations. Prior work has identified a relationship between the release of firm-specific news and the return volatility of individual stocks: For instance, GroßKlußmann and Hautsch [2011] and Smales [2012] find that the release of highly relevant news induces an increase in return volatility, with negative news having a greater impact than positive news.

\section{$<$ Insert Figure 1 $>$}

I quantitatively evaluate this relationship using an ordinary least square (OLS) specification. In the first instance, I examine the direct relationship between changes in VIX and the release of news:

$$
\Delta V I X_{t}=\beta_{0}+\beta_{1} N e w s_{t}+\varepsilon_{t}
$$

Where $\Delta V I X_{t}$ is the change in VIX during the interval $t, N e w s_{t}$ is the aggregated sentiment of news items released during interval $t$, and $\varepsilon_{t}$ is the error term for interval $t$. I then specifically test for the asymmetric news reaction by disaggregating news releases into a positive and negative component:

$$
\Delta V I X_{t}=\beta_{0}+\beta_{1} N e w s_{t}^{+}+\beta_{2} N e w s_{t}^{-}+\varepsilon_{t}
$$

Where $\Delta V I X_{t}$ is the change in VIX during the interval $t, \mathrm{NeWs}_{t}{ }^{+}$is the aggregated sentiment of news items released during interval $t$ conditional on positive news (i.e. News $s_{t}>0$ ) and 0 otherwise. 
$\mathrm{News}_{t}{ }^{-}$is the aggregated sentiment of news items released during interval $t$ conditional on negative news (i.e. $\mathrm{News}_{t}>0$ ) and 0 otherwise.

$<$ Insert Table 2>

Table $2^{5}$ reports the estimated results for the overall relationship between changes in VIX and the sentiment of news release, using a daily time interval. The estimated relation for the whole sample is:

$$
\Delta V I X_{t}=0.020-3.41 N e w s_{t}
$$

The intercept is not significantly different from zero, suggesting that VIX will not change in the absence of news releases with aggregate sentiment in either direction. The coefficient for news sentiment is significant at the $1 \%$ level, where the sign of the coefficient confirms that news sentiment has a negative relationship with changes in implied volatility, i.e. positive (negative) news is related to a decline (increase) in VIX. Examining the relationship for each annual sub-period reveals that it evolves over time; news sentiment has an insignificant relation with changes in VIX during periods of low implied volatility (2003-2005) and a much stronger connection during periods of high implied volatility. In particular, the period surrounding the global financial crisis (GFC) of 2007-2009 produces highly significant coefficients and evidence of a stronger association (high $R^{2}$ ). Results for the hourly and 5-minute interval reveal that the relationship between news sentiment and changes in implied volatility becomes weaker as the time interval is reduced; the association is significant only for the period 2006-2009 when considering hourly intervals, and is not significant in any individual year when considering 5-minute intervals. This in contrast to the findings by GroßKlußmann and Hautsch [2011] and Smales [2012] who note almost instantaneous reactions of individual stock prices to firm-specific news, and suggests that the assimilation of aggregated news takes some time to process.

\section{$<$ Insert Table 3>}

Table 3 reports the estimated results for the relationship between changes in VIX and news sentiment disaggregated into positive and negative news. For daily time intervals, the estimated relation over the whole sample is:

$$
\Delta V I X_{t}=-0.127-1.129 N e w s_{t}^{+}+5.600 N e w s_{t}^{-}+\varepsilon_{t}
$$

Again, the intercept is not significantly different from zero when considering the overall sample, suggesting that VIX will not change in the absence of news releases with aggregate positive

\footnotetext{
${ }^{5}$ The results presented in Table 2 and 3 use average news sentiment during period $t$, analysis using the sum of news sentiment produces qualitatively similar results.
} 
or negative sentiment. However, during the 2007-09 period (coinciding with the GFC) the intercept is negative and significant, indicating that implied volatility falls in the absence of news sentiment; thus, during the period of generally high-volatility and negative news sentiment it could be said that "no news is good news".

The coefficients for positive and negative news sentiment are significant and confirm exante expectations. In particular, positive news relates to a decline in VIX and negative news occurs in periods of increasing implied volatility. In addition, there is evidence of an asymmetric relationship whereby the change in VIX is larger in periods of negative news. Considering the annual sub-periods reveals that the relationship is relatively constant over time, although the magnitude of the coefficients does vary somewhat. In 2002, and 2008, (periods of stock market declines and sharply increasing VIX) positive news has the more significant association; one possible explanation been that during periods that witness a high degree of negative news, as commonly occurs when markets are falling and volatility is increasing, any additional negative news will have less impact than positive news that is seized on by the market to initiate a 'relief rally'. Analysis of intra-day intervals reveals that the relationship between negative news and changes in VIX is positive and significant for both hourly and 5-minute intervals. When considering the annual sub-periods this association is significant only for the period around the GFC (2006-2009) for the hourly interval, and only in 2008 for the 5-minute interval.

\section{Conclusion}

Investor sentiment indicators such as VIX are frequently utilised to gauge market conditions. Market participants utilize pre-processed news sentiment indicators, such as that developed by Ravenpack, to summarize large amounts of real-time data and to inform their investment strategy. This paper examines the relationship between those two types of sentiment indicators. Investigation of the contemporaneous relationship demonstrates that a significant negative relationship exists between changes in VIX and aggregated news sentiment; the association is stronger during periods of high-volatility, such as during the financial crisis of 2007-2009. There is evidence of asymmetry where the magnitude of the change in VIX is larger during intervals of negative news, although this asymmetry apparently reverses when there is an excessive amount of bad news. Possible extensions of this topic could involve the development of effective trading strategies and the application to individual stocks, or other asset classes such as exchange-traded foreign exchange or government bond futures. 


\section{References}

Black, F. , 1976, Studies of stock price volatility changes, Proceedings of the 1976 American Statistical Association, Business and economic statistics section, 177-181

Dzielinski, M., 2011, News sensitivity and the cross-section of stock returns, NCCR Finrisk working paper no. 719

Fleming, J., B. Ostdiek and R.E. Whaley, 1995, Predicting stock market volatility: A new measure, Journal of Futures Markets, 15, 265-302

Giot, P., 2005, Relationships between implied volatility indexes and stock index returns, Journal of Portfolio Management, 26, 12-17

Groß-Klußmann, A., and N. Hautsch, 2011, When machines read the news: Using automated text analytics to quantify high frequency news-implied market reactions, Journal of Empirical Finance, 18, 321-340

Patell, J., and M. Wolfson, 1984, The intraday speed of adjustment of stock prices to earnings and dividend announcements, Journal of Financial Economics, 13, 223-252

Smales, L.A., 2012, Non-scheduled news arrival and high-frequency stock market dynamics: Evidence from the Australian Stock Exchange, Working paper

Tetlock, P.C., M. Saar-Tsechansky, and S. Macskassy, 2008, More than words: Quantifying language to measure firms' fundamentals, Journal of Finance, 63, 1437-1467

Whaley, R.E., 2000, The investor fear gauge, Journal of Portfolio Management, 26, 12-17

Whaley, R.E., 2009, Understanding the VIX, Journal of Portfolio Management, 35, 98-105

Woodruff, C.S., and A.J. Senchack, 1988, Intraday price-volume adjustments of NYSE stocks to unexpected earnings, Journal of Finance, 43, 467-491

Web-sourced Material:

Ravenpack methodology - http://www.ravenpack.com/

VIX Methodology - http://www.cboe.com/micro/vix/vixwhite.pdf 


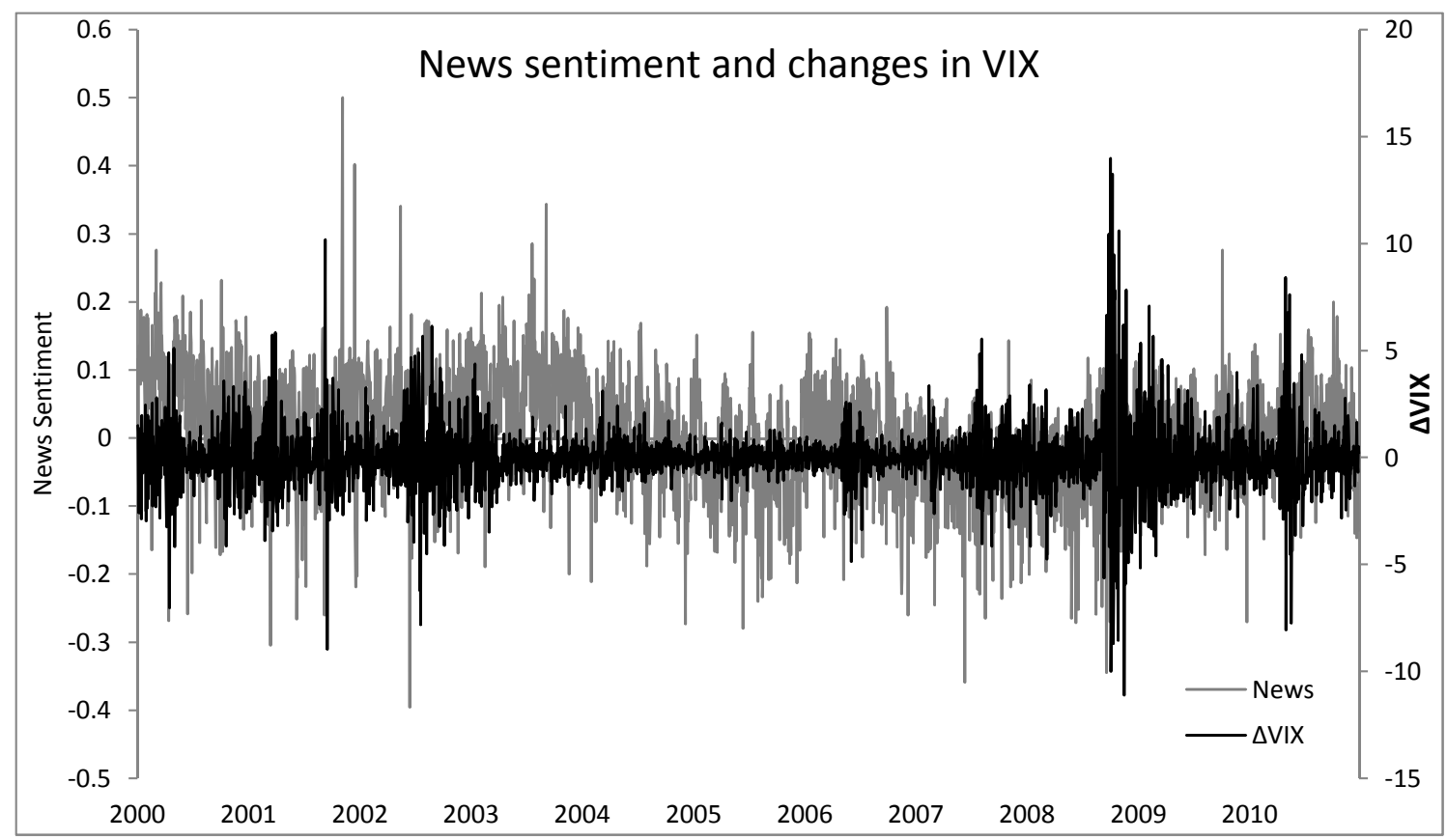

Fig. 1. Daily aggregate news sentiment (left-axis) and changes in VIX (right-axis) 
Table 1

\section{Descriptive Statistics}

Descriptive statistics, for daily intervals, are provided for Aggregated News Sentiment and the Implied Volatility Index (VIX). The table reports the average aggregate number of news items for S\&P 500 constituents each day. Each news item, categorised using Ravenpack's MCQ classification, is value-weighted in-line with the respective S\&P500 Index weighting. The average daily aggregate news sentiment is reported together with the minimum and maximum level of this aggregate measure of news sentiment. The mean level of VIX is provided along with the level of VIX at the 10th and 90th percentile. The mean, and standard deviation of the daily change in VIX is also provided. For the S\&P 500 Index I report the mean level, the mean daily return and the standard deviation of returns. Summary data is provided for each of the years in the sample. Sample Period: Jan 2000 - Dec 2010

\begin{tabular}{|c|c|c|c|c|c|c|c|c|c|c|c|c|}
\hline \multirow[b]{2}{*}{ Period } & \multirow[b]{2}{*}{ Obs. } & \multicolumn{4}{|c|}{ News Sentiment (MCQ) } & \multicolumn{6}{|c|}{ Volatility Index (VIX) } & \multirow[b]{2}{*}{ Max Change } \\
\hline & & No. Items & $\begin{array}{l}\text { Ave. } \\
\text { MCQ }\end{array}$ & Min MCQ & $\begin{array}{l}\text { Max } \\
\text { MCQ }\end{array}$ & Mean Level & $\begin{array}{c}\text { 10th } \\
\text { Percentile }\end{array}$ & $\begin{array}{c}\text { 90th } \\
\text { Percentile }\end{array}$ & $\begin{array}{l}\text { Mean } \\
\text { Change }\end{array}$ & SD Change & Min Change & \\
\hline ALL: $2000-2010$ & 2760 & 800 & 0.43 & -55.1 & 196.2 & 23.19 & 12.17 & 35.73 & -0.003 & 1.56 & -11.11 & 13.99 \\
\hline 2000 & 250 & 356 & 4.88 & -21.5 & 60.3 & 26.09 & 21.57 & 30.94 & 0.018 & 1.51 & -7.03 & 5.11 \\
\hline 2001 & 250 & 550 & -1.36 & -30.7 & 21.3 & 28.64 & 23.28 & 35.62 & -0.032 & 1.69 & -8.97 & 10.18 \\
\hline 2002 & 251 & 447 & -0.36 & -29.5 & 34.1 & 30.72 & 21.44 & 42.69 & 0.039 & 1.78 & -7.81 & 6.14 \\
\hline 2003 & 250 & 480 & 1.47 & -26.8 & 30.3 & 24.12 & 16.95 & 36.01 & -0.059 & 0.97 & -3.50 & 4.38 \\
\hline 2004 & 249 & 756 & 1.76 & -21.4 & 17.4 & 15.49 & 13.12 & 18.28 & -0.021 & 0.70 & -1.76 & 3.12 \\
\hline 2005 & 252 & 774 & 3.91 & -16.5 & 15.8 & 12.80 & 11.16 & 14.94 & -0.004 & 0.55 & -2.03 & 1.62 \\
\hline 2006 & 251 & 804 & 3.29 & -25.1 & 19.2 & 12.82 & 10.97 & 15.85 & -0.003 & 0.81 & -4.86 & 2.59 \\
\hline 2007 & 251 & 1058 & -5.54 & -36.0 & 14.3 & 17.52 & 10.92 & 25.20 & 0.044 & 1.26 & -4.15 & 5.54 \\
\hline 2008 & 252 & 1169 & -4.01 & -34.5 & 12.3 & 32.74 & 19.71 & 61.94 & 0.069 & 2.97 & -11.11 & 13.99 \\
\hline 2009 & 252 & 1149 & 0.25 & -12.2 & 27.5 & 31.59 & 22.08 & 45.28 & -0.08 & 1.66 & -5.16 & 7.07 \\
\hline 2010 & 252 & 1015 & 1.35 & -12.7 & 26.5 & 22.58 & 17.25 & 29.39 & -0.01 & 1.70 & -8.06 & 8.41 \\
\hline
\end{tabular}


Table 2

Contemporaneous relationship between implied volatility index and aggregated news sentiment

The contemporaneous relationship between aggregated news sentiment (News) and changes in the implied volatility index ( $\triangle$ VIX) is reported at daily, hourly and 5-minute intervals. Aggregated news sentiment is measured as the average Ravenpack MCQ score in each interval. In each case the dependent variable is change in VIX ( $V I X$ ) for the given interval length. Standard errors are reported in parentheses. Sample Period: Jan 2000 - Dec 2010

\begin{tabular}{|c|c|c|c|c|c|c|c|c|c|c|c|c|c|c|c|c|}
\hline \multirow{2}{*}{$\begin{array}{l}\text { Sample } \\
\text { Period }\end{array}$} & \multicolumn{6}{|c|}{ Daily Interval } & \multicolumn{5}{|c|}{ Hourly Interval } & \multicolumn{5}{|c|}{ 5-minute interval } \\
\hline & Obs & Constant & & News & & $\mathrm{R}^{2}$ & Obs & Constant & News & & $\mathrm{R}^{2}$ & Obs & Constant & News & & $\mathrm{R}^{2}$ \\
\hline \multirow[t]{2}{*}{ All } & 2760 & 0.006 & & -1.636 & $* * *$ & 0.072 & 22080 & -0.004 & -0.142 & $* * *$ & 0.001 & 242880 & 0.002 & -0.007 & $* * *$ & 0.000 \\
\hline & & $(0.03)$ & & $(0.24)$ & & & & $(0.01)$ & $(0.03)$ & & & & $(0.001)$ & $(0.002)$ & & \\
\hline \multirow[t]{2}{*}{2000} & 250 & 0.048 & & -0.888 & & 0.003 & 2000 & 0.004 & -0.066 & & 0.000 & 22000 & -0.001 & 0.000 & & 0.000 \\
\hline & & $(0.45)$ & & $(1.04)$ & & & & $(0.02)$ & $(0.09)$ & & & & $(0.003)$ & $(0.005)$ & & \\
\hline \multirow[t]{2}{*}{2001} & 250 & -0.078 & & -3.402 & $* *$ & 0.080 & 2000 & -0.014 & -0.225 & $* *$ & 0.004 & 22000 & -0.003 & 0.002 & & 0.000 \\
\hline & & $(0.11)$ & & $(1.51)$ & & & & $(0.02)$ & $(0.09)$ & & & & $(0.002)$ & $(0.005)$ & & \\
\hline \multirow[t]{2}{*}{2002} & 251 & 0.028 & & -3.200 & $*$ & 0.013 & 2008 & -0.002 & -0.200 & $*$ & 0.005 & 22088 & 0.002 & -0.004 & & 0.000 \\
\hline & & $(0.11)$ & & $(1.75)$ & & & & $(0.02)$ & $(0.12)$ & & & & $(0.005)$ & $(0.009)$ & & \\
\hline \multirow[t]{2}{*}{2003} & 250 & -0.056 & & -0.174 & & 0.008 & 2000 & -0.008 & -0.159 & & 0.006 & 22000 & 0.000 & -0.002 & & 0.000 \\
\hline & & $(0.06)$ & & $(0.97)$ & & & & $(0.01)$ & $(0.15)$ & & & & $(0.001)$ & $(0.002)$ & & \\
\hline \multirow[t]{2}{*}{2004} & 249 & -0.030 & & -0.397 & & 0.001 & 1992 & -0.004 & -0.044 & & 0.001 & 21912 & -0.006 & -0.008 & & 0.000 \\
\hline & & $(0.05)$ & & $(0.83)$ & & & & $(0.01)$ & $(0.04)$ & & & & $(0.003)$ & $(0.006)$ & & \\
\hline \multirow[t]{2}{*}{2005} & 252 & -0.012 & & -0.275 & & 0.001 & 2016 & -0.006 & -0.067 & & 0.001 & 22176 & -0.006 & -0.013 & $*$ & 0.000 \\
\hline & & $(0.04)$ & & $(0.68)$ & & & & $(0.01)$ & $(0.06)$ & & & & $(0.002)$ & $(0.007)$ & & \\
\hline \multirow[t]{2}{*}{2006} & 251 & -0.093 & & -2.713 & $* * *$ & 0.067 & 2008 & -0.004 & -0.050 & & 0.001 & 22088 & -0.007 & -0.006 & $*$ & 0.001 \\
\hline & & $(0.06)$ & & (0.98) & & & & $(0.01)$ & $(0.04)$ & & & & $(0.008)$ & $(0.003)$ & & \\
\hline \multirow[t]{2}{*}{2007} & 251 & -0.266 & $*$ & -5.599 & $* * *$ & 0.070 & 2008 & -0.011 & -0.185 & $* *$ & 0.003 & 22088 & -0.002 & -0.018 & $* * *$ & 0.001 \\
\hline & & $(0.14)$ & & $(2.06)$ & & & & $(0.01)$ & $(0.09)$ & & & & $(0.002)$ & $(0.005)$ & & \\
\hline \multirow[t]{2}{*}{2008} & 252 & -0.571 & $* *$ & -15.96 & $* * *$ & 0.131 & 2016 & -0.001 & -0.390 & $* * *$ & 0.003 & 22176 & 0.002 & -0.012 & $*$ & 0.000 \\
\hline & & $(0.24)$ & & (3.93) & & & & $(0.03)$ & $(0.20)$ & & & & $(0.003)$ & $(0.006)$ & & \\
\hline \multirow[t]{2}{*}{2009} & 252 & -0.024 & & -20.93 & $* * *$ & 0.223 & 2016 & -0.008 & -0.318 & $* *$ & 0.005 & 22176 & -0.003 & -0.005 & & 0.000 \\
\hline & & $(0.10)$ & & (3.13) & & & & $(0.02)$ & $(0.16)$ & & & & $(0.001)$ & $(0.005)$ & & \\
\hline \multirow[t]{2}{*}{2010} & 252 & 0.045 & & -4.225 & & 0.007 & 2016 & 0.004 & -0.262 & & 0.001 & 22176 & 0.001 & -0.006 & & 0.000 \\
\hline & & $(0.12)$ & & (3.21) & & & & $(0.02)$ & $(0.18)$ & & & & $(0.002)$ & $(0.005)$ & & \\
\hline
\end{tabular}

*** denotes significance of the coefficient estimates at the $1 \%$ level, ${ }^{* *}$ at the $5 \%$ level, and ${ }^{*}$ at the $10 \%$ level. 
Table 3

Contemporaneous relationship between implied volatility index and positive and negative news sentiment

The contemporaneous relationship between aggregated positive news sentiment (News ${ }^{+}$), aggregated negative news sentiment (News ${ }^{-}$) and changes in the implied volatility index $(\Delta V I X)$ is reported at daily, hourly and 5-minute intervals. Positive (negative) aggregated news sentiment is measured as the average value-weighted Ravenpack MCQ score News) in each interval, conditional on News $>0$ (News $<0$ ). In each case the dependent variable is change in VIX $(\triangle V I X)$ for the given interval length. Standard errors are reported Sample Period: Jan 2000 - Dec 2010

\begin{tabular}{|c|c|c|c|c|c|c|c|c|c|c|c|c|c|c|c|c|c|c|c|}
\hline \multirow{2}{*}{$\begin{array}{l}\text { Sample } \\
\text { Period }\end{array}$} & \multicolumn{7}{|c|}{ Daily Interval } & \multicolumn{7}{|c|}{ Hourly Interval } & \multicolumn{5}{|c|}{ 5-Minute Interval } \\
\hline & Constant & & News $^{+}$ & & News ${ }^{-}$ & & $R^{2}$ & Constant & & News $^{+}$ & & News ${ }^{-}$ & & $\mathrm{R}^{2}$ & Constant & News $^{+}$ & News ${ }^{-}$ & & $\mathrm{R}^{2}$ \\
\hline \multirow[t]{2}{*}{ All } & -0.096 & & -0.841 & $* * *$ & 4.146 & $* * *$ & 0.052 & -0.007 & & -0.103 & $* *$ & 0.170 & $* * *$ & 0.001 & -0.001 & -0.003 & 0.011 & $* * *$ & 0.000 \\
\hline & $(0.06)$ & & $(0.30)$ & & $(0.61)$ & & & $(0.01)$ & & $(0.05)$ & & $(0.04)$ & & & $(0.006)$ & $(0.002)$ & $(0.002)$ & & \\
\hline \multirow[t]{2}{*}{2000} & -0.109 & & -0.629 & & 6.631 & $* *$ & 0.021 & 0.016 & & -0.118 & & 0.024 & & 0.001 & 0.007 & -0.004 & 0.003 & & 0.000 \\
\hline & $(0.14)$ & & $(1.34)$ & & (3.19) & & & $(0.02)$ & & $(0.11)$ & & $(0.16)$ & & & $(0.020)$ & $(0.006)$ & $(0.008)$ & & \\
\hline \multirow[t]{2}{*}{2001} & -0.140 & $* *$ & -1.400 & & 4.307 & $* *$ & 0.060 & 0.001 & & -0.131 & & 0.358 & $* *$ & 0.004 & 0.001 & -0.001 & 0.006 & & 0.000 \\
\hline & $(0.07)$ & & $(3.48)$ & & $(2.07)$ & & & $(0.02)$ & & $(0.13)$ & & $(0.17)$ & & & $(0.020)$ & $(0.008)$ & $(0.007)$ & & \\
\hline \multirow[t]{2}{*}{2002} & 0.114 & & -1.720 & & 5.395 & & 0.015 & -0.005 & & -0.171 & & 0.217 & $* *$ & 0.005 & 0.002 & -0.003 & 0.005 & & 0.000 \\
\hline & (0.17) & & $(0.82)$ & & $(3.69)$ & & & $(0.02)$ & & $(0.13)$ & & $(0.10)$ & & & $(0.030)$ & $(0.012)$ & $(0.010)$ & & \\
\hline \multirow[t]{2}{*}{2003} & 0.042 & & -1.982 & & 2.050 & & 0.008 & -0.024 & & -0.030 & & 0.271 & $*$ & 0.008 & -0.121 & -0.002 & 0.005 & & 0.000 \\
\hline & $(0.10)$ & & $(1.85)$ & & $(1.68)$ & & & $(0.01)$ & & $(0.09)$ & & $(0.16)$ & & & (0.185) & $(0.006)$ & $(0.006)$ & & \\
\hline \multirow[t]{2}{*}{2004} & 0.011 & & -0.298 & & 1.897 & & 0.003 & -0.004 & & -0.047 & & 0.041 & & 0.001 & -0.007 & -0.006 & 0.009 & & 0.000 \\
\hline & $(0.07)$ & & $(1.22)$ & & $(2.14)$ & & & $(0.01)$ & & $(0.09)$ & & $(0.06)$ & & & $(0.020)$ & $(0.009)$ & $(0.007)$ & & \\
\hline \multirow[t]{2}{*}{2005} & -0.006 & & -0.082 & & 1.318 & & 0.001 & -0.005 & & -0.073 & & 0.063 & & 0.001 & -0.222 & -0.002 & 0.020 & $* * *$ & 0.001 \\
\hline & $(0.06)$ & & $(0.86)$ & & $(2.48)$ & & & $(0.01)$ & & $(0.14)$ & & $(0.08)$ & & & $(0.193)$ & $(0.007)$ & $(0.006)$ & & \\
\hline \multirow[t]{2}{*}{2006} & -0.063 & & -2.290 & & 4.436 & * & 0.031 & -0.015 & $*$ & -0.105 & & 0.123 & $*$ & 0.004 & -0.006 & -0.004 & 0.008 & $* * *$ & 0.001 \\
\hline & $(0.08)$ & & $(1.65)$ & & $(2.65)$ & & & $(0.01)$ & & $(0.09)$ & & $(0.07)$ & & & $(0.008)$ & $(0.003)$ & $(0.003)$ & & \\
\hline \multirow[t]{2}{*}{2007} & -0.244 & $* *$ & -2.510 & & 5.311 & $* * *$ & 0.082 & -0.010 & & -0.133 & & 0.190 & $* *$ & 0.003 & -0.158 & -0.008 & 0.024 & $* * *$ & 0.001 \\
\hline & $(0.13)$ & & $(1.55)$ & & $(2.02)$ & & & $(0.02)$ & & $(0.27)$ & & $(0.08)$ & & & (0.184) & $(0.009)$ & $(0.007)$ & & \\
\hline \multirow[t]{2}{*}{2008} & -0.323 & $* *$ & -32.42 & $* *$ & 12.26 & $* * *$ & 0.132 & -0.043 & & -0.158 & & 0.701 & $* * *$ & 0.005 & -0.216 & -0.012 & 0.031 & $* * *$ & 0.001 \\
\hline & $(0.13)$ & & (15.68) & & $(5.02)$ & & & $(0.04)$ & & $(0.46)$ & & $(0.21)$ & & & $(0.265)$ & $(0.013)$ & $(0.011)$ & & \\
\hline \multirow[t]{2}{*}{2009} & -0.072 & $* *$ & -18.847 & $* * *$ & 22.70 & $* * *$ & 0.241 & -0.037 & & -0.074 & & 1.227 & $* * *$ & 0.005 & -0.007 & -0.005 & 0.045 & $* * *$ & 0.001 \\
\hline & $(0.03)$ & & $(6.47)$ & & $(5.74)$ & & & $(0.02)$ & & $(0.22)$ & & (0.39) & & & $(0.014)$ & $(0.006)$ & $(0.008)$ & & \\
\hline \multirow[t]{2}{*}{2010} & -0.021 & & -2.212 & & 8.954 & & 0.018 & -0.018 & & -0.033 & & 0.659 & & 0.002 & -0.166 & -0.010 & 0.056 & $* * *$ & 0.002 \\
\hline & $(0.15)$ & & $(4.35)$ & & $(7.57)$ & & & $(0.02)$ & & $(0.28)$ & & $(0.34)$ & & & $(0.15)$ & $(0.007)$ & $(0.009)$ & & \\
\hline
\end{tabular}

*** denotes significance of the coefficient estimates at the $1 \%$ level, ** at the $5 \%$ level, and * at the $10 \%$ level. 